\title{
The Mortality in Emergency Department Sepsis Score as a Predictor of 1-Month Mortality among Adult Patients with Sepsis: Weighing the Evidence
}

\author{
Bayushi Eka Putra' ${ }^{1}$ and Ling Tiah ${ }^{2}$ \\ ${ }^{1}$ Faculty of Medicine, University Indonesia, Salemba Raya 6, Jakarta 10430, Indonesia \\ ${ }^{2}$ Accident and Emergency Department, Changi General Hospital, Singapore 2 Simei Street 3, Singapore 529889 \\ Correspondence should be addressed to Ling Tiah; ling_tiah@cgh.com.sg
}

Received 16 June 2013; Accepted 15 July 2013

Academic Editors: C. D. Boucek, F. Folke, and G. Volpicelli

Copyright (C) 2013 B. Eka Putra and L. Tiah. This is an open access article distributed under the Creative Commons Attribution License, which permits unrestricted use, distribution, and reproduction in any medium, provided the original work is properly cited.

\begin{abstract}
Objective. To evaluate the performance of Mortality in Emergency Department Sepsis (MEDS) score in comparison to biomarkers as a predictor of mortality in adult emergency department (ED) patients with sepsis. Methods. A literature search was performed using PubMed, ScienceDirect, SpringerLink, and Ovid databases. Studies were appraised by using the C2010 Consensus Process for Levels of Evidence for prognostic studies. The respective values for area under the curve (AUC) were obtained from the selected articles. Results. Four relevant articles met the selection process. Three studies defined the 1-month mortality as death occurring within 28 days of ED presentation, while the remaining one subcategorised the outcome measure as (5-day) early and (6- to 30-day) late mortality. In all four studies, the MEDS score performed better than the respective comparators (C-reactive protein, lactate, procalcitonin, and interleukin-6) in predicting mortality with an AUC ranging from 0.78 to 0.89 across the studies. Conclusion. The MEDS score has a better prognostic value than the respective comparators in predicting 1-month mortality in adult ED patients with suspected sepsis.
\end{abstract}

\section{Case}

You have just attended to a 70-year-old male patient who presented to the emergency department (ED) with fever for 2 days associated with dysuria. He has a history of hypertension with previous ischaemic stroke and currently stays at a nursing home. On examination, he is lethargic but of normal mental status. His vital signs are as follows: temperature $38.8^{\circ} \mathrm{C}$, heart rate 96 beats $/ \mathrm{min}$, blood pressure $110 / 70 \mathrm{mmHg}$, and respiratory rate 22 breaths/min. Urinalysis suggests a urinary tract infection. The white cell count is 16,000 per $\mathrm{mm}^{3}$ with $10 \%$ bands while the platelet count is 140,000 per $\mathrm{mm}^{3}$. Blood and urine cultures are sent and the appropriate antibiotics administered. Blood specimens for serum lactate and procalcitonin are also sent as part of the routine septic work-up in your ED, but the results are not available yet. Concerned about the risk of mortality and the applicability of early goal-directed therapy (EGDT) in this case, you wonder if there are any validated clinical prediction tools that can risk stratify ED patients with sepsis in a more timely manner.

\section{Background}

Sepsis and its spectrum of clinical entities remain one of the common critical illnesses encountered in the emergency department (ED) with an estimated mortality rate of $20-$ $30 \%$ in population-based studies $[1,2]$. Timely identification with early institution of appropriate therapy for sepsis is essential for improved outcomes among these patients [35]. Unfortunately, the severity of the condition may not be apparent at initial contact with ED personnel. This is made even more challenging in an evolving ED practice, where care is increasingly being delivered in overcrowded situations with limited resources, particularly in urban settings with a heavy workload [6, 7].

In light of the above, the Mortality in Emergency Department Sepsis (MEDS) score was developed to address the 


\begin{tabular}{|c|c|c|c|}
\hline Variables for MEDS score & Points & & \\
\hline Rapidly terminal comorbid illness & 6 & & \\
\hline \multirow[t]{2}{*}{ Age $>65$ years } & \multirow[t]{2}{*}{3} & & \\
\hline & & MEDS score range & 28-day mortality rate \\
\hline Tachypnea or hypoxemia & 3 & $0-4$ & $1.1 \%$ \\
\hline Septic shock & 3 & $5-7$ & $4.4 \%$ \\
\hline Platelet count $<150,000 / \mathrm{mm}^{3}$ & 3 & $8-12$ & $9.3 \%$ \\
\hline Neutrophil bands $>5 \%$ & 3 & $13-15$ & $16.1 \%$ \\
\hline Lower respiratory infection & 2 & $>15$ & $39 \%$ \\
\hline Altered mental status & 2 & & \\
\hline Nursing home resident & 2 & & \\
\hline
\end{tabular}

MEDS: Mortality in Emergency Department Sepsis

FIGURE 1: MEDS score and its prediction for 28-day mortality [8].

need for an early risk stratification tool for sepsis that is simple to use and applicable at the ED [8]. Based on the scores computed from nine variables drawn from patient profile, clinical findings at presentation, and initial laboratory examination, it predicts the 28-day mortality rate for ED patients with sepsis (Figure 1). While the MEDS score is not the only clinical scoring system developed for use in the ED for predicting mortality, it is the most relevant for patients with suspected sepsis presenting to the $\operatorname{ED~}[6,9]$.

The performance of the MEDS score has been validated in various populations and appears to compare favourably in some reports with other clinical scores like the Acute Physiology and Chronic Health Evaluation (APACHE) II, the Confusion, Urea, Respiratory Rate, Blood Pressure, 65 Years or Older (CURB-65), and the modified Rapid Emergency Medicine Score (mREMS) [10-12]. However, the discriminatory power of the MEDS score in predicting mortality does not seem to be consistent across different risk groups, being more accurate for low-risk patients and less for those in the high-risk group [13, 14]. This is thought to be attributable to the low mortality rate among the MEDS score's derivation cohort, thereby inherently underestimating the risk when it is applied to populations with higher baseline mortality rates like those with severe sepsis and septic shock [13, 15].

For such high-risk groups, biomarkers of infectionsuch as procalcitonin (PCT) and C-reactive protein (CRP) and serum lactate as alternative independent predictors of mortality in sepsis have been studied in various clinical settings [16-18]. A combined use has also been suggested to improve prognostic accuracy among severely septic patients compared to their respective singular applications [19-21]. While these biomarkers are relevant in the management of such patients, their usefulness may be offset by limited availability in some ED settings due to cost and infrastructure issues. We aimed to evaluate the performance of the MEDS score in comparison to these biochemical markers as a predictor of mortality in adult ED patients with sepsis.

\section{Clinical Question}

What is the prognostic value of the MEDS score, when compared to PCT, CRP, or serum lactate, for 1-month mortality among adult patients presenting to the ED with sepsis and its clinical spectrum?

\section{Methods}

4.1. Evidence Search. Based on the formulated clinical question, we performed a search in the following databases for articles published in English from May 31, 1993, to May 31, 2013: PubMed, ScienceDirect, SpringerLink, and Ovid (Table 1). Eligible studies were then selected after filtering through a set of inclusion and exclusion criteria.

4.2. Critical Appraisal and Data Extraction. Appraisal of the selected studies was conducted independently by the two authors based on the C2010 Consensus Process for Levels of Evidence for prognostic studies [22]. Any disagreements were resolved through consensus. For studies in which receiver operating characteristic (ROC) curves were used to depict the predictive models, we extracted values for the area under the ROC curve (AUC) for comparison. Where available, diagnostic parameters like sensitivity, specificity, positive predictive value (PPV), and negative predictive value (NPV) were also extracted for comparison.

\section{Results}

5.1. Characteristics of Selected Studies. Our search process resulted in the identification of four articles that fulfilled our final selection criteria (Figure 2). Two studies were conducted in Asia, one in the United Kingdom, and one in The Netherlands. The characteristics of the included studies with regard to their respective study design, population profile, determinant of prognosis, and its comparator(s) 
TABLE 1: Search strategy.

\begin{tabular}{|c|c|}
\hline Database & Search terms \\
\hline PubMed & $\begin{array}{l}\text { MEDS [All Fields] AND (("sepsis" [MeSH Terms] OR "sepsis" [All Fields]) OR sirs [All Fields] OR septic [All Fields]) } \\
\text { AND ("lactic acid" [MeSH Terms] OR ("lactic" [All Fields] AND "acid" [All Fields]) OR "lactic acid" [All Fields] OR } \\
\text { "lactate" [All Fields] OR "lactates" [MeSH Terms] OR "lactates" [All Fields]) OR "c-reactive protein" [All Fields] OR } \\
\text { ("procalcitonin" [Supplementary Concept] OR "procalcitonin" [All Fields])) AND ("mortality" [Subheading] OR } \\
\text { "mortality" [All Fields] OR "mortality" [MeSH Terms]) AND ("adult" [MeSH Terms] OR "adult" [All Fields]) AND } \\
\text { ("emergencies" [MeSH Terms] OR "emergencies" [All Fields] OR "emergency" [All Fields]) AND (Case Reports [ptyp] } \\
\text { OR Clinical Trial [ptyp] OR Comparative Study [ptyp] OR Validation Studies [ptyp] OR Classical Article [ptyp] OR } \\
\text { Journal Article [ptyp]) }\end{array}$ \\
\hline ScienceDirect & $\begin{array}{l}\text { ALL (MEDS AND (sepsis OR sirs OR septic) AND (lactate OR “c-reactive protein" OR procalcitonin) AND mortality } \\
\text { AND adult AND emergency) AND LIMIT-TO (contenttype, "1,2" "Journal") AND LIMIT-TO (topics, "emergency } \\
\text { department") }\end{array}$ \\
\hline SpringerLink & $\begin{array}{l}\text { MEDS AND (sepsis OR sirs OR septic) AND (lactate OR “c-reactive protein" OR procalcitonin) AND mortality AND } \\
\text { adult AND emergency within Medicine Critical Care and Emergency Medicine Sepsis Article }\end{array}$ \\
\hline Ovid & $\begin{array}{l}\text { MEDS AND (sepsis OR sirs OR septic) AND (lactate OR “c-reactive protein" OR procalcitonin) AND mortality AND } \\
\text { adult AND emergency \{Including Limited Related Terms\} limit } 1 \text { to "all adult" (19 plus years); to original articles [Limit } \\
\text { not valid in Ovid MEDLINE(R), Ovid MEDLINE(R) In-Process, Ovid MEDLINE(R) Daily Update, Ovid } \\
\text { OLDMEDLINE(R); records were retained] }\end{array}$ \\
\hline
\end{tabular}

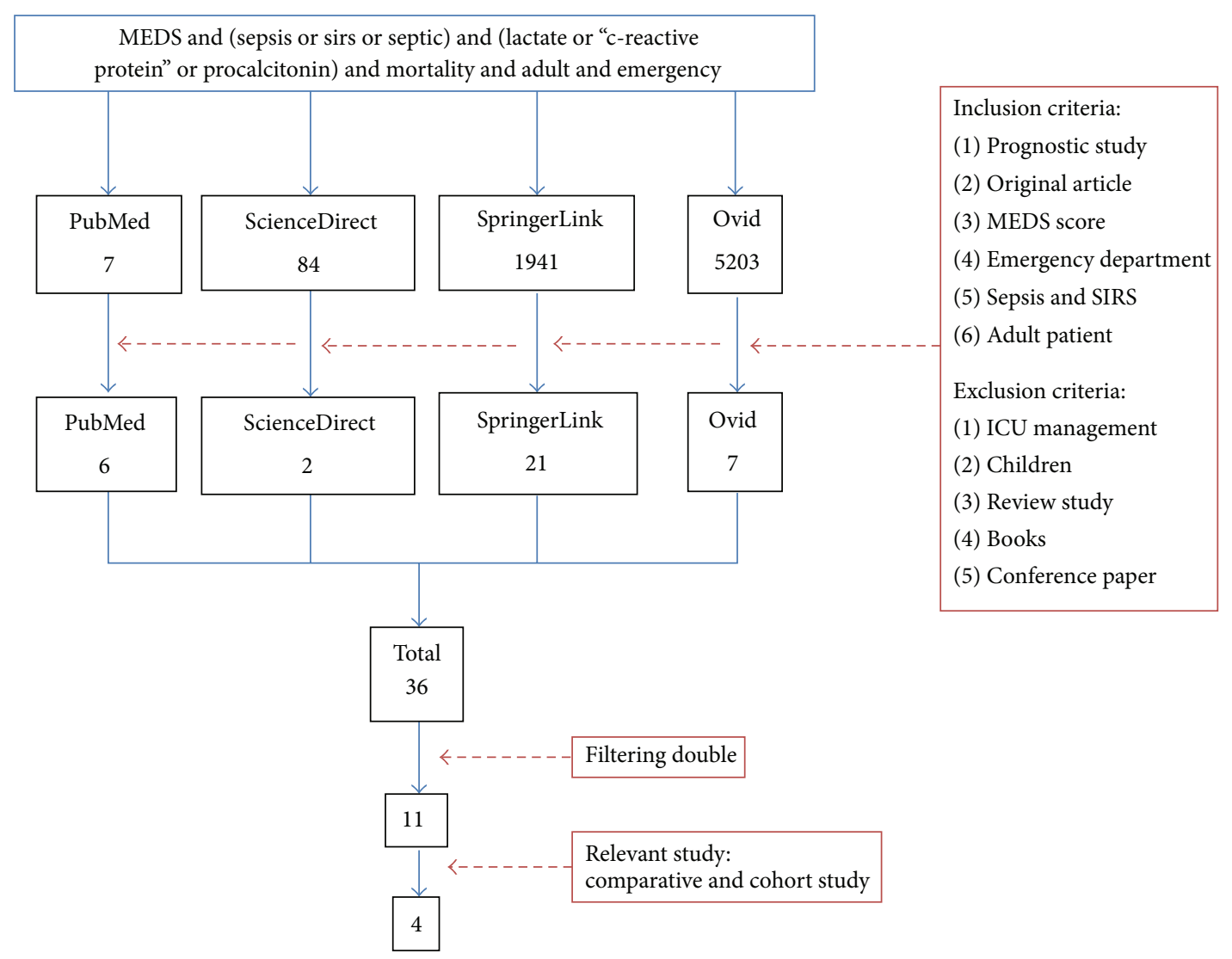

FIGURE 2: Flowchart of evidence search and selection process.

and outcome were summarised in Table 2. Based on the C2010 Consensus Process with its predetermined factors for quality assessment of prognostic studies, the validity of results was good for one study and fair for the remaining three (Table 3).
5.2. Prognostic Determinant and Comparators. Three of the four studies evaluated the performance of the MEDS score in comparison to their respective choice of biomarkers as a predictor of mortality [23-25] while the remaining one used a modified MEDS score computed from eight variables instead 
TABLE 2: Summary of included studies.

\begin{tabular}{|c|c|c|c|c|}
\hline & Hermans et al., 2012 [23] & Lee et al., 2008 [24] & Vorwerk et al., 2009 [26] & Zhao et al., 2013 [25] \\
\hline Study design & Retrospective cohort study & Prospective cohort study & Retrospective cohort study & Prospective cohort study \\
\hline \multirow{2}{*}{$\begin{array}{l}\text { Study } \\
\text { population }\end{array}$} & $\begin{array}{l}\text { (i) One centre (tertiary) } \\
\text { (ii) Adult ED patients }(>18 \\
\text { years old) }\end{array}$ & $\begin{array}{l}\text { (i) One centre (tertiary) } \\
\text { (ii) Adult ED patients }(\geq 15 \\
\text { years old) }\end{array}$ & $\begin{array}{l}\text { (i) Two centres (one urban } \\
\text { teaching and one district } \\
\text { general) } \\
\text { (ii) Adult ED patients (>16 } \\
\text { years old) }\end{array}$ & $\begin{array}{l}\text { (i) One centre (tertiary) } \\
\text { (ii) Adult ED patients }(>18 \\
\text { patients) }\end{array}$ \\
\hline & $\begin{array}{l}\text { Sample size of } 331 \text { patients } \\
\text { (i) Sepsis }(62 \%) \\
\text { (ii) Severe sepsis }(30 \%) \\
\text { (iii) Septic shock (4\%) }\end{array}$ & $\begin{array}{l}\text { Sample size of } 525 \text { patients } \\
\text { (i) Sepsis }(76 \%) \\
\text { (ii) Severe sepsis }(19 \%) \\
\text { (iii) Septic shock }(5 \%)\end{array}$ & $\begin{array}{l}\text { Sample size of } 307 \text { patients } \\
\text { (i) No further information } \\
\text { about categorisation by } \\
\text { severity of sepsis }\end{array}$ & $\begin{array}{l}\text { Sample size of } 501 \text { patients } \\
\text { (i) Sepsis }(64 \%) \\
\text { (ii) Severe sepsis }(31 \%) \\
\text { (iii) Septic shock }(5 \%)\end{array}$ \\
\hline $\begin{array}{l}\text { Prognostic } \\
\text { determinant }\end{array}$ & MEDS score & MEDS score & Abbreviated MEDS score & MEDS score \\
\hline \multirow{5}{*}{ Comparator } & C-reactive protein & C-reactive protein & - & C-reactive protein \\
\hline & - & Procalcitonin & - & Procalcitonin \\
\hline & Lactate & - & Lactate & - \\
\hline & - & - & - & Interleukin-6 \\
\hline & - & - & - & MEDS + procalcitonin \\
\hline Outcome & 28-day mortality & $\begin{array}{l}\text { 5-day (early) and 6- to } \\
\text { 30-day (late) mortality }\end{array}$ & 28-day mortality & 28-day mortality \\
\hline
\end{tabular}

ED: emergency department; MEDS score: Mortality in Emergency Department Sepsis score.

TABLE 3: Critical appraisal of included studies* .

\begin{tabular}{|c|c|c|c|c|}
\hline & $\begin{array}{l}\text { Hermans et al., } \\
\quad 2012[23]\end{array}$ & $\begin{array}{l}\text { Lee et al., } \\
2008[24]\end{array}$ & $\begin{array}{l}\text { Vorwerk et al., } \\
2009[26]\end{array}$ & $\begin{array}{l}\text { Zhao et al., } \\
2013 \text { [25] }\end{array}$ \\
\hline $\begin{array}{l}\text { (A) C2010 Consensus Process for Levels of Evidence } \\
\text { (LOE) for prognostic and retrospective studies }\end{array}$ & $\begin{array}{l}\text { Retrospective } \\
\text { (LOE P3) }\end{array}$ & $\begin{array}{l}\text { Prospective } \\
\text { (LOE P1) }\end{array}$ & $\begin{array}{l}\text { Retrospective } \\
\text { (LOE P3) }\end{array}$ & $\begin{array}{l}\text { Prospective } \\
\text { (LOE P1) }\end{array}$ \\
\hline
\end{tabular}

(B) Assessment of study quality based on the following factors:

(i) Was the sample of patients representative?

(ii) Were outcomes measured in the same (preferably

blinded) objective way in both groups?

(iii) Were known confounders identified and appropriately controlled for?

(iv) Was followup of patients sufficiently long and complete (eg $>80 \%)$ ?

\begin{tabular}{ll} 
Yes & Yes \\
No & No \\
Yes & Yes \\
Yes & Yes \\
Fair & Fair \\
& \\
\hline
\end{tabular}

(C) Validity of study results

(presence of all 4 factors = good; presence of above 3

factors = fair; presence of above 2 factors = poor;

presence of above 1 or less factors = study should be excluded from further review)

*Adapted from Levels of Evidence used for the review of Resuscitation Science for 2010 from C2010 Consensus Process
(http://www.heart.org/idc/groups/heart-public/@wcm/@private/@ecc/documents/downloadable/ucm_308199.pdf).

of nine (without the neutrophil bands) [26]. Zhao et al. also assessed the impact on the prognostic value of the MEDS score by combining it with one of the biomarkers [25].

5.3. Outcome. Three studies defined the 1-month mortality as death occurring within 28 days of ED presentation $[23,25,26]$ while Lee et al. subcategorised the outcome measure as (5day) early and (6- to 30-day) late mortality [24]. In all four studies, the MEDS score performed better than the respective comparators in predicting mortality with an AUC ranging from 0.78 to 0.89 across the studies (Table 4).

The study by Hermans et al. demonstrated the superiority of the MEDS score in its discriminative ability for 28-day mortality (AUC $=0.81$ ) when compared to CRP (AUC = 0.68) [23]. Serum lactate, with an AUC $=0.75$, seemed to be potentially useful as well but as it was done in less than $15 \%$ of the study population, its prognostic value in comparison to the MEDS score remains uncertain [23]. Lee et al. found the MEDS score to have the largest AUC in comparison to CRP 
TABLE 4: Area under the ROC curve for MEDS score and respective biomarkers for prediction of mortality.

\begin{tabular}{|c|c|c|c|c|c|}
\hline & \multicolumn{5}{|c|}{ Area under the ROC curve $(95 \% \mathrm{CI})$} \\
\hline & \multirow{2}{*}{$\begin{array}{c}\text { Hermans et al., } 2012 \text { [23] } \\
\text { 28-day mortality }\end{array}$} & \multicolumn{2}{|c|}{ Lee et al., $2008^{\mathrm{a}}[24]$} & \multirow{2}{*}{$\begin{array}{c}\text { Vorwerk et al., } 2009 \text { [26] } \\
\text { 28-day mortality }\end{array}$} & \multirow{2}{*}{$\begin{array}{c}\text { Zhao et al., } 2013 \text { [25 } \\
\text { 28-day mortality }\end{array}$} \\
\hline & & 5-day mortality & 6- to 30-day mortality & & \\
\hline MEDS score & $0.81(0.73-0.88)$ & 0.89 & 0.82 & $0.82(0.78-0.87)^{\mathrm{b}}$ & $0.78(0.73-0.83)$ \\
\hline C-reactive protein & $0.68(0.58-0.78)$ & 0.68 & 0.64 & - & $0.66(0.61-0.72)$ \\
\hline Procalcitonin & - & 0.76 & 0.73 & - & $0.68(0.63-0.74)$ \\
\hline Lactate & $0.75(0.6-0.9)$ & - & - & $0.62(0.54-0.7)$ & - \\
\hline Interleukin-6 & - & - & - & - & $0.69(0.64-0.74)$ \\
\hline MEDS + procalcitonin & - & - & - & - & $0.81(0.77-0.86)$ \\
\hline
\end{tabular}

and PCT for early as well as late mortality [24]. The MEDS score also correlated well with the classification of clinical severity of sepsis [24]. The abbreviated MEDS score evaluated by Vorwerk et al. was found to have a better performance as a predictor of 28-day mortality $(\mathrm{AUC}=0.81)$ when compared to serum lactate $(\mathrm{AUC}=0.62)$ among patients enrolled from the urban teaching centre [26]. A MEDS score of 13 and above was found to correlate well with those with severe sepsis and septic shock with a specificity of $85.3 \%$, PPV of $70.4 \%$, and NPV of $79.5 \%$ by Zhao et al. [25]. In the same study, the combined use of the MEDS score and PCT improved the AUC for severity of sepsis from 0.793 to $0.852(P<0.001)$ and the AUC for 28 -day mortality from 0.776 to $0.813(P=0.008)$ [25].

\section{Discussion}

Based on the previous results, the MEDS score remains a useful prognostic tool with better discriminative ability compared to the isolated use of CRP, PCT, and serum lactate for predicting 1-month mortality in adult ED patients with suspected sepsis across its clinical spectrum. A combined use of the MEDS score with PCT or serum lactate may help to improve the predictive accuracy, particularly in highrisk patients whose initial presentation at ED may be subtle $[23,25]$. This added vantage to the performance of the MEDS score, however, may not be applicable in some ED settings where measurements of such biomarkers are not available due to limited resources and costs. Even if available, the additional time spent waiting for results may compromise the timeliness of the MEDS score.

Although the MEDS score is simple and applicable at bedside in the ED, there are still some challenges when trying to score some of the components. The inclusion of neutrophil bands as one of the variables is one such example. This is because many laboratories are now automating the analysis of haematological tests, and identification of neutrophil bands, conducted manually, is no longer routinely done. The work by Vorwerk et al. demonstrated a favourable performance of the abbreviated MEDS score despite excluding the bands [26].

"Terminal illness" is the other variable that has been highlighted as a potential issue. The highest weightage with 6 points is being accorded, but users lament the lack of objectivity in its determination [25]. The study by Hermans et al. demonstrated the dilemma with this component where patients with advanced stage of malignancies and terminal conditions would score high in the MEDS score, thereby naturally predicting a very high risk of 1-month mortality. Yet some understandably did not receive standard EGDT due to existence of advanced medical directives, patients' choice for palliative management or medical futility [23]. However, it should be remembered that the MEDS score is designed for use as a prognostic tool to estimate mortality risk. While providing guidance for therapy, it is not meant to directly dictate treatment for patients and should not stand alone as a decision tool for how septic patients should be managed [23]. Patient preferences and clinical judgment by physicians are essential in guiding appropriate therapeutic decisions.

\section{Clinical Bottom Line}

The MEDS score has a good prognostic value in predicting 1month mortality in adult ED patients with suspected sepsis. Combining its use with selected biomarkers of infection may improve its performance in settings where the biomarkers are being measured as part of the routine ED work-up for septic patients. Modifying some of the variables may further enhance relevance and applicability of the MEDS score. Finally, the MEDS score has to be used in conjunction with sound clinical judgment to guide therapeutic decisions like implementation of EDGT for the group of patients who would benefit most from it.

\section{Conflict of Interests}

There is no conflict of interests to disclose.

\section{Acknowledgment}

The authors would like to express their gratitude to Dr. Rahul Goswami for sharing his perspective and providing valuable inputs for the draft of this paper.

\section{References}

[1] D. C. Angus, W. T. Linde-Zwirble, J. Lidicker, G. Clermont, J. Carcillo, and M. R. Pinsky, "Epidemiology of severe sepsis in 
the United States: analysis of incidence, outcome, and associated costs of care," Critical Care Medicine, vol. 29, no. 7, pp. 1303-1310, 2001.

[2] G. S. Martin, D. M. Mannino, S. Eaton, and M. Moss, "The epidemiology of sepsis in the United States from 1979 through 2000," The New England Journal of Medicine, vol. 348, no. 16, pp. 1546-1554, 2003.

[3] E. Rivers, B. Nguyen, S. Havstad et al., "Early goal-directed therapy in the treatment of severe sepsis and septic shock," The New England Journal of Medicine, vol. 345, no. 19, pp. 1368-1377, 2001.

[4] H. B. Nguyen, S. W. Corbett, R. Steele et al., "Implementation of a bundle of quality indicators for the early management of severe sepsis and septic shock is associated with decreased mortality," Critical Care Medicine, vol. 35, no. 4, pp. 1105-1112, 2007.

[5] A. Focht, A. E. Jones, and T. J. Lowe, "Early goal-directed therapy: improving mortality and morbidity of sepsis in the emergency department," Joint Commission Journal on Quality and Patient Safety/Joint Commission Resources, vol. 35, no. 4, pp. 186-191, 2009.

[6] J. Hargrove and H. B. Nguyen, "Bench-to-bedside review: outcome predictions for critically ill patients in the emergency department," Critical Care, vol. 9, no. 4, pp. 376-383, 2005.

[7] J. A. Barrett, S. W. Glickman, L. B. Caram, D. Freeman, C. Oien, G. Molinar et al., "185: utility of triage heart rate and shock index in predicting infection in emergency department patients with systemic inflammatory response syndrome criteria," Annals of Emergency Medicine, vol. 50, article S59, no. 3, 2007.

[8] N. I. Shapiro, R. E. Wolfe, R. B. Moore, E. Smith, E. Burdick, and D. W. Bates, "Mortality in Emergency Department Sepsis (MEDS) score: a prospectively derived and validated clinical prediction rule," Critical Care Medicine, vol. 31, no. 3, pp. 670675, 2003.

[9] M. Brabrand, L. Folkestad, N. G. Clausen, T. Knudsen, and J. Hallas, "Risk scoring systems for adults admitted to the emergency department: a systematic review," Scandinavian Journal of Trauma, Resuscitation and Emergency Medicine, vol. 18, no. 1, article 8, 2010.

[10] C.-C. Chen, C.-F. Chong, Y.-L. Liu, K.-C. Chen, and T.-L. Wang, "Risk stratification of severe sepsis patients in the emergency department," Emergency Medicine Journal, vol. 23, no. 4, pp. 281-285, 2006.

[11] M. D. Howell, M. W. Donnino, D. Talmor, P. Clardy, L. Ngo, and N. I. Shapiro, "Performance of severity of illness scoring systems in emergency department patients with infection," Academic Emergency Medicine, vol. 14, no. 8, pp. 709-714, 2007.

[12] J. D. Sankoff, M. Goyal, D. F. Gaieski et al., "Validation of the Mortality in Emergency Department Sepsis (MEDS) score in patients with the systemic inflammatory response syndrome (SIRS)," Critical Care Medicine, vol. 36, no. 2, pp. 421-426, 2008.

[13] H. B. Nguyen, J. E. Banta, T. W. Cho et al., "Mortality predictions using current physiologic scoring systems in patients meeting criteria for early goal-directed therapy and the severe sepsis resuscitation bundle," Shock, vol. 30, no. 1, pp. 23-28, 2008.

[14] C. R. Carpenter, S. M. Keim, S. Upadhye, and H. B. Nguyen, "Risk stratification of the potentially septic patient in the emergency department: the mortality in the emergency department sepsis (MEDS) score," Journal of Emergency Medicine, vol. 37, no. 3, pp. 319-327, 2009.

[15] A. E. Jones, K. Saak, and J. A. Kline, "Performance of the Mortality in emergency department Sepsis score for predicting hospital mortality among patients with severe sepsis and septic shock," American Journal of Emergency Medicine, vol. 26, no. 6, pp. 689-692, 2008.

[16] A. Luzzani, E. Polati, R. Dorizzi, A. Rungatscher, R. Pavan, and A. Merlini, "Comparison of procalcitonin and C-reactive protein as markers of sepsis," Critical Care Medicine, vol. 31, no. 6, pp. 1737-1741, 2003.

[17] M. D. De Kruif, M. Limper, H. Gerritsen et al., "Additional value of procalcitonin for diagnosis of infection in patients with fever at the emergency department," Critical Care Medicine, vol. 38, no. 2, pp. 457-463, 2010.

[18] N. A. Hisamuddin and K. Azlan, "The use of laboratory and physiological parameters in predicting mortality in sepsis induced hypotension and septic shock patients attending the emergency department," Medical Journal of Malaysia, vol. 67, no. 3, pp. 259-264, 2012.

[19] A. Oberholzer, S. M. Souza, S. K. Tschoeke et al., "Plasma cytokine measurements augment prognostic scores as indicators of outcome in patients with severe sepsis," Shock, vol. 23, no. 6, pp. 488-493, 2005.

[20] K. Tschaikowsky, M. Hedwig-Geissing, G. G. Braun, and M. Radespiel-Troeger, "Predictive value of procalcitonin, interleukin-6, and C-reactive protein for survival in postoperative patients with severe sepsis," Journal of Critical Care, vol. 26, no. 1, pp. 54-64, 2011.

[21] J. Wilhelm, S. Hettwer, D. Hammer, M. Schürmann, A. Christoph, M. Amoury et al., "Outcome prediction using clinical scores and biomarkers in patients with presumed severe infection in the emergency department," Medizinische Klinik, Intensivmedizin und Notfallmedizin, vol. 107, no. 7, pp. 558-563, 2012.

[22] P. T. Morley, "Evidence evaluation worksheets: the systematic reviews for the evidence evaluation process for the 2010 International Consensus on Resuscitation Science," Resuscitation, vol. 80, no. 7, pp. 719-721, 2009.

[23] M. A. W. Hermans, P. Leffers, L. M. Jansen, Y. C. Keulemans, and P. M. Stassen, "The value of the Mortality in Emergency Department Sepsis (MEDS) score, C reactive protein and lactate in predicting 28-day mortality of sepsis in a Dutch emergency department," Emergency Medicine Journal, vol. 29, no. 4, pp. 295-300, 2012.

[24] C.-C. Lee, S.-Y. Chen, C.-L. Tsai et al., "Prognostic value of mortality in emergency department sepsis score, procalcitonin, and C-reactive protein in patients with sepsis at the emergency department," Shock, vol. 29, no. 3, pp. 322-327, 2008.

[25] Y. Zhao, C. Li, and Y. Jia, "Evaluation of the mortality in emergency department sepsis score combined with procalcitonin in septic patients," American Journal of Emergency Medicine, vol. 31, no. 7, pp. 1086-1091, 2013.

[26] C. Vorwerk, B. Loryman, T. J. Coats et al., "Prediction of mortality in adult emergency department patients with sepsis," Emergency Medicine Journal, vol. 26, no. 4, pp. 254-258, 2009. 


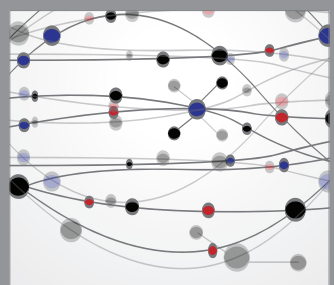

The Scientific World Journal
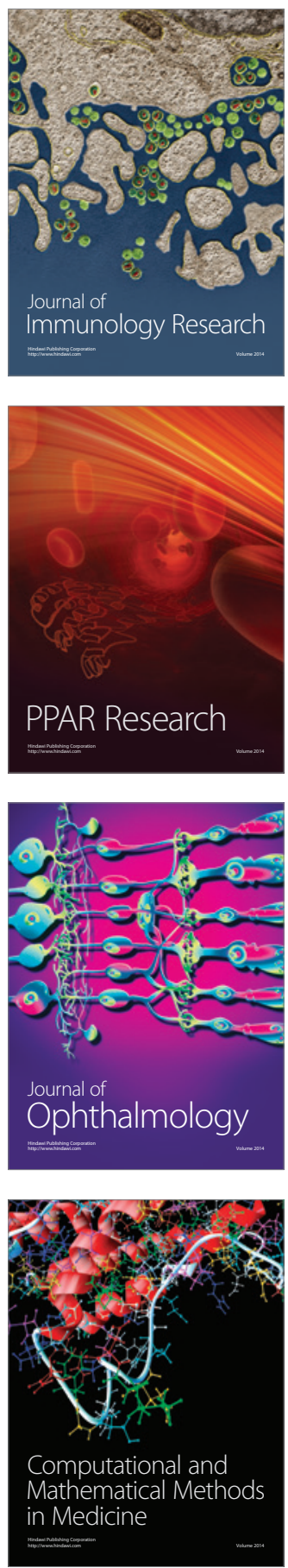

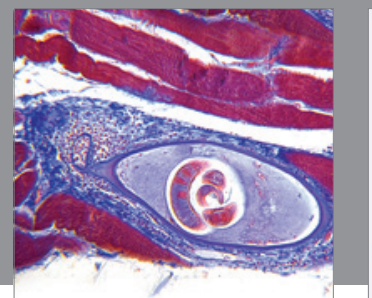

Gastroenterology

Research and Practice
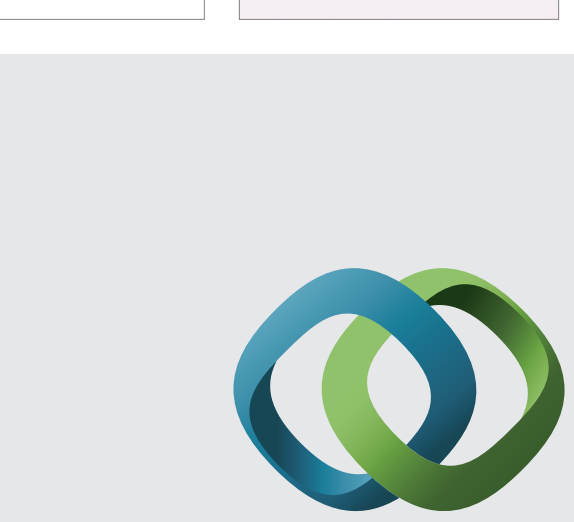

\section{Hindawi}

Submit your manuscripts at

http://www.hindawi.com
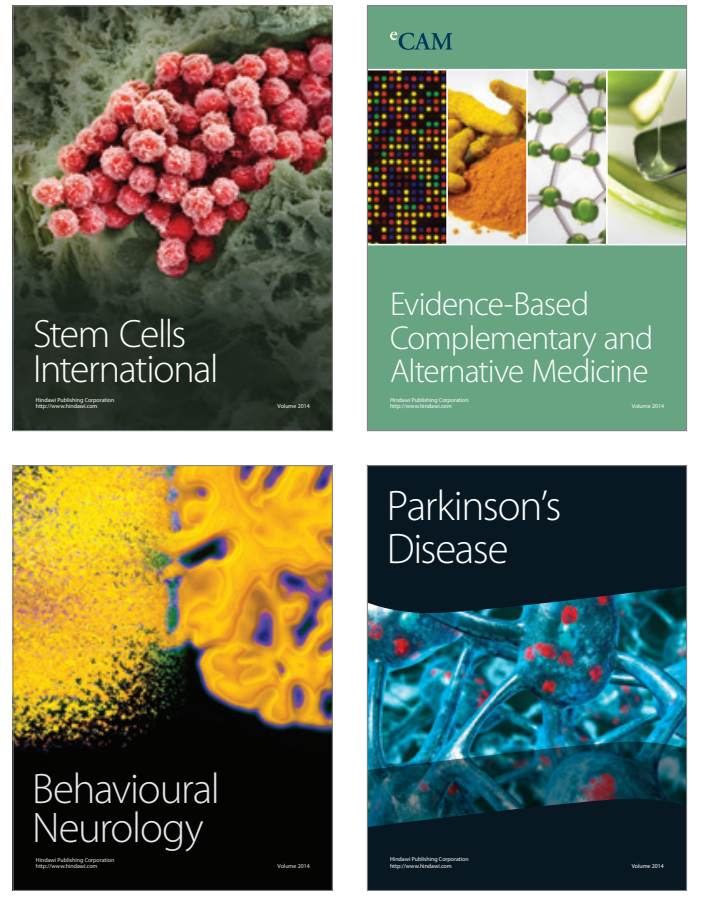
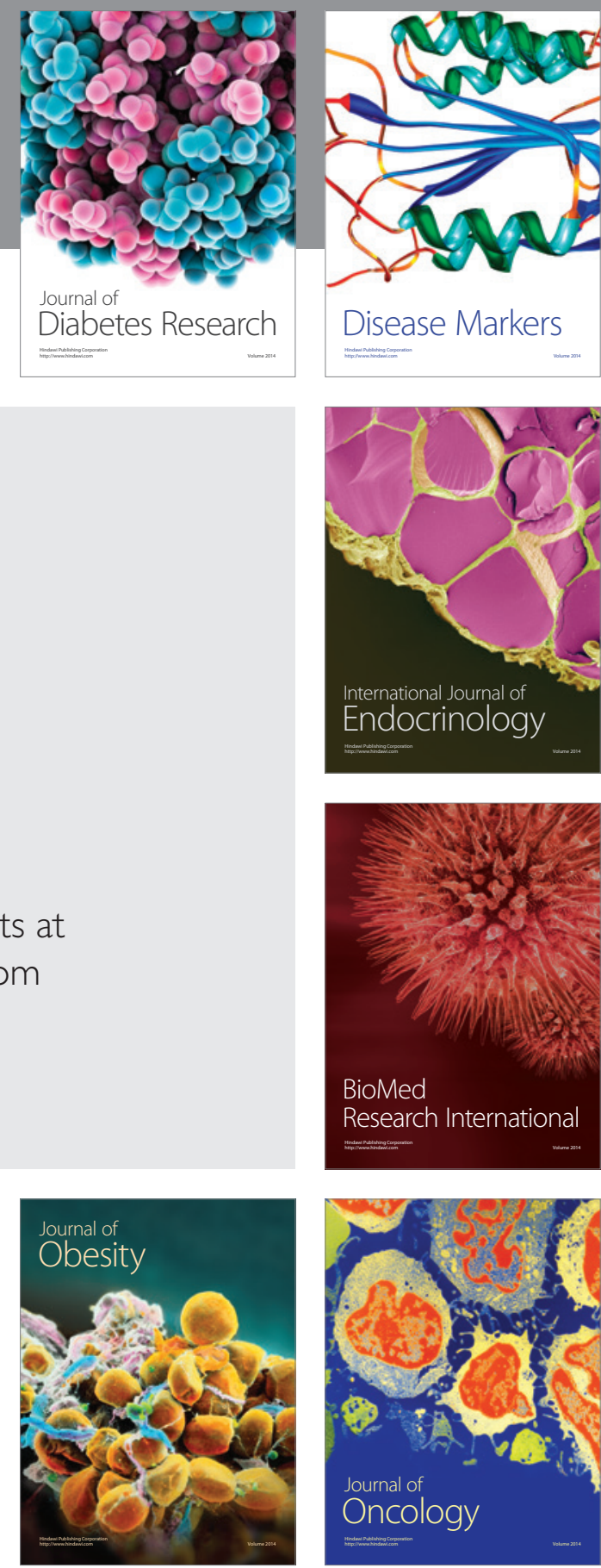

Disease Markers
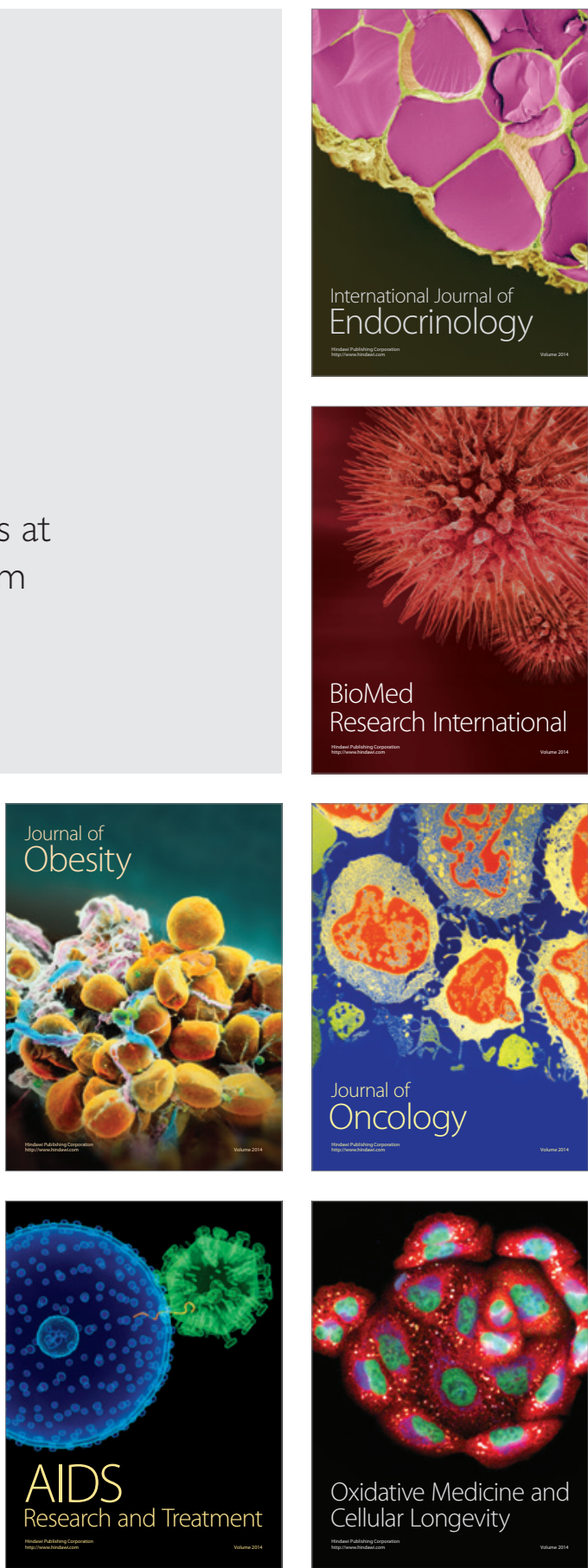